\title{
Failure Assessment Diagram (FAD) analysis of fatigue test results for X65 welded joints
}

\author{
Hsin Jen Hoh", John Hock Lye Pang, and Kin Shun Tsang \\ School of Mechanical \& Aerospace Engineering, Nanyang Technological University, 50 Nanyang Avenue, Singapore 639798, Singapore
}

\begin{abstract}
Offshore pipelines transfer oil and gas from seabed to production facility on the surface. The long pipelines are formed by welding of pipe segments, where these welded joints are a source of stress concentration and defects from which fatigue cracks can grow. This work aims to study the behaviour of deep fatigue cracks. In this current work, finite-element based on a parametric study of four-point bending is used to assess the stress intensity factors (SIFs) of deep surface cracks in X65 specimens, while considering local limit load the remaining load bearing ligament. These deep cracks take on a non-regular shape and have widths that exceed that of the specimen. They will be compared to empirical expressions from derived standards such as British Standards BS7910, which may be more conservative. The existing large flaw is also assessed via the failure assessment diagram (FAD). The effects of limit load solutions and reference stresses used to determine the FAD diagram will be discussed.
\end{abstract}

\section{Introduction}

The degradation of transmission pipelines systems due to fatigue by environmental loads or corrosion leads to formation of cracks that initiate from regions of high stresses such as weld joints. These joints connect pipe segments to form a long pipeline, but are sources of stress concentration and defects from which fatigue cracks can grow.

\subsection{Background}

In prior testing [1], butt-welded X65 offshore pipes (outer diameter 32" and 1" thickness) were cut into fatigue coupons $(t=25.4 \mathrm{~mm}, b=100 \mathrm{~mm})$. A four-point bending test $(\mathrm{L}=240 \mathrm{~mm}, \mathrm{l}=120 \mathrm{~mm}$ ) was setup (Fig. 1) such that tensile stresses occurred at the pipe surface with weld cap. The four-point bending fatigue test was conducted at various loads (load ratio 0.1) until the coupons could no longer support fatigue cyclic loading. The load and their corresponding fracture surface were recorded in Table 1.
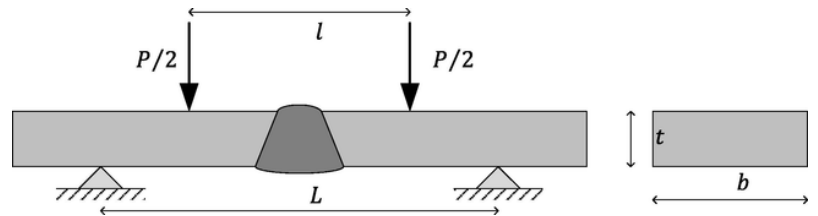

Fig. 1. Four-point fatigue bending setup of X65 steel coupons [1].

While linear elastic fracture mechanics approaches such as the solutions for semi-elliptical cracks in plates or pipes [2-3] apply for smaller sized defects, they do not apply to these deep or larger sized cracks, when plastic collapse becomes significant.

This work will employ the Failure Assessment Diagram (FAD) to determine if an existing deep flaw in X65 steel pipe is acceptable by: investigating SIFs of a varying depth edge crack that has progressed beyond specimen width; and understanding the effect of plasticity in such large flaws.

Table 1. Bending fatigue fracture surfaces [1]

\begin{tabular}{|c|c|c|}
\hline No & $\begin{array}{c}\text { Stress } \\
\text { range MPa }\end{array}$ & Fracture surfaces \\
\hline 1 & 292.5 & \\
\hline 2 & 320 & \\
\hline 3 & 337.5 & \\
\hline 5 & 382.5 & \\
\hline & & \\
\hline & & \\
\hline
\end{tabular}

Corresponding author: hjhoh@ntu.edu.sg

(C) The Authors, published by EDP Sciences. This is an open access article distributed under the terms of the Creative Commons Attribution License 4.0 (http://creativecommons.org/licenses/by/4.0/). 


\subsection{Failure Assessment Diagram (FAD)}

The BS7910:2013 [4] outlines fracture assessment by means of a Failure Assessment Diagram (FAD). The FAD establishes the relationship between brittle fracture (by fracture parameter $\mathrm{K}_{\mathrm{r}}$, equation 1) with local plasticity (plastic collapse parameter $\mathrm{L}_{\mathrm{r}}$, equation 2). Plastic collapse could be in the form of global or local collapse [5].

$K_{r}=\frac{K_{\mathrm{I}}}{K_{\mathrm{IC}}}$

$L_{r}=\frac{\sigma_{\mathrm{app}}}{\sigma_{\text {limit }}}=\frac{\sigma_{\mathrm{ref}}}{\sigma_{\mathrm{Y}}}$

The fracture parameter is an indicator of fracture under linear elastic conditions, while the plastic collapse parameter could be defined as ratio of applied load to limit load (equation 2), where limit load refers to the remote load that will cause spread of plasticity. Equation 2 also show the relation of the limit load to the parameter reference stress $\sigma_{\text {ref }}$ parameter, also commonly used to determine the plastic collapse parameter.

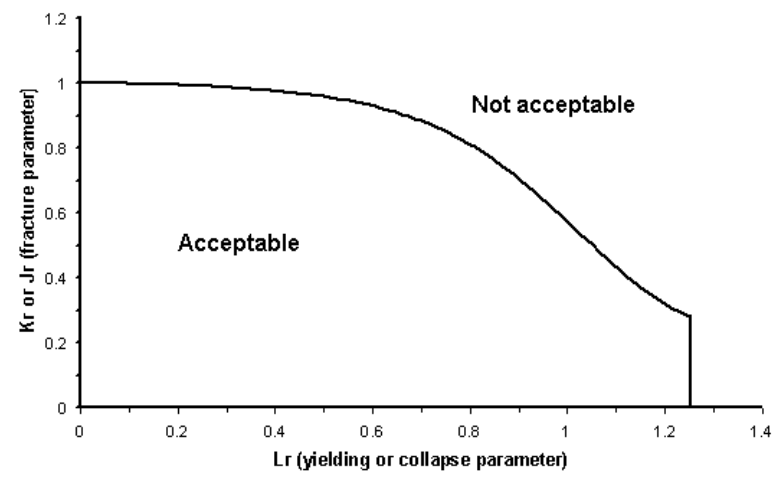

Fig. 2. A typical failure assessment diagram (FAD) [6].

The FAD typically comprises an assessment envelope given by the equation of a curve $K_{r}=f\left(L_{r}\right)$, and a cut-off value of $\mathrm{L}_{\mathrm{r}}, \mathrm{L}_{\mathrm{r}, \max }$ (Fig. 2). If the assessment point plotted lies within the area bounded by the axes, assessment line and $\mathrm{L}_{\mathrm{r}, \max }$ line, the flaw is acceptable. The simplest (option 1) FAD in the BS7910:2013 does not require stress-strain data. The governing equations of the assessment envelope for this case are

$f\left(L_{r}\right)=\left(1+L_{r}^{2} / 2\right)^{-\frac{1}{2}}\left[0.3+0.7 e^{-\mu L_{r}^{6}}\right]$ for $L_{r} \leq 1$

$f\left(L_{r}\right)=L_{r}^{(N-1) /(2 N)}$

for $1<\mathrm{L}_{\mathrm{r}}<\mathrm{L}_{\mathrm{r} \text {,max }}(4)$

$f\left(L_{r}\right)=0$

for $\mathrm{L}_{\mathrm{r}} \geq \mathrm{L}_{\mathrm{r} \text {,max }}$

where

$\mu=\min \left(0.001 \frac{E}{\sigma_{Y}}, 0.6\right)$

$N=0.3\left(1-\frac{\sigma_{\mathrm{Y}}}{\sigma_{\mathrm{u}}}\right)$

$L_{r, \max }=\frac{\sigma_{\mathrm{Y}}+\sigma_{\mathrm{u}}}{2 \sigma_{\mathrm{Y}}}$
The more complicated options outlined (options 2 and 3) require more input in terms of material and stress analysis with higher accuracy. For example, the option 2 approach requires detailed stress-strain data, especially at strains below $1 \%$. The FAD envelope needs to be determined at least for certain values of $\mathrm{L}_{\mathrm{r}}$. Option 3 requires elastic and elastic-plastic analysis to determine J-integral values.

The analysis requires material properties such as yield strength $\sigma_{\mathrm{Y}}$, ultimate tensile strength $\sigma_{\mathrm{u}}$, elastic modulus $E$ and fracture toughness $K_{\mathrm{IC}}$. The yield strength and ultimate tensile strength of the X65 steel were obtained via relation to hardness [7] $\left(\sigma_{\mathrm{Y}}=550\right.$ and $\left.\sigma_{\mathrm{u}}=633 \mathrm{MPa}\right)$, while the fracture toughness of $280 \mathrm{MPa}$ $\sqrt{\mathrm{m}}$ was used [8].

To determine the location of the evaluation point on the $\mathrm{FAD}$, requires $\mathrm{K}_{\mathrm{I}}$ as well as limit load or reference stress. Some solutions for reference stress are available from the BS7910:2013. For the current study of large flaws, the closest crack geometries would be that of a semi-elliptical surface crack (Fig. 3) and an extended surface flaw (Fig. 4).

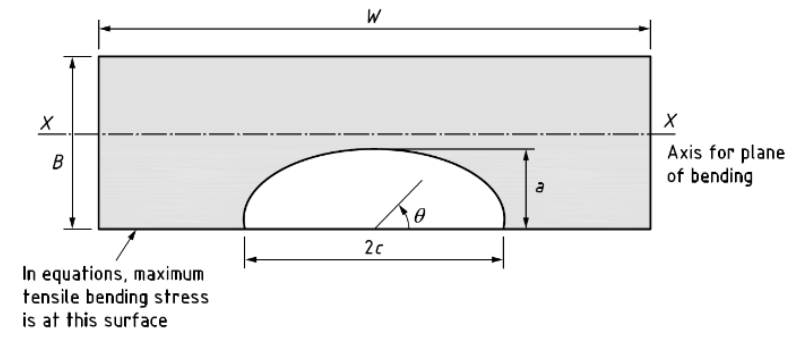

Fig. 3. Geometry of semi-elliptical surface crack in plate [4].

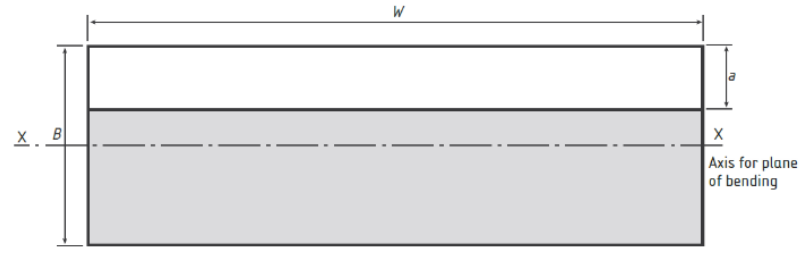

Fig. 4. Geometry of extended flaw in plate [4].

The reference stress is given as

$\sigma_{\mathrm{ref}}=\frac{2 P_{\mathrm{b}}}{3\left(1-\alpha^{\prime \prime}\right)^{2}}$

where $P_{\mathrm{b}}$ is the primary bending stress while $\alpha^{\prime \prime}$ for a semi-elliptical surface crack is

$\alpha^{\prime \prime}=\frac{2 a / t}{1+\left(\frac{t}{c}\right)} \quad$ for $w \geq 2(c+t)$

$\alpha^{\prime \prime}=2\left(\frac{a}{t}\right)\left(\frac{c}{w}\right)$ for $w<2(c+t)$

while $\alpha^{\prime \prime}$ for an extended surface flaw is

$\alpha^{\prime \prime}=\frac{a}{B}$

However, these current empirical expressions from the BS7910:2013 in determining this reference stress are overly conservative. 
In the current work, the $\mathrm{K}_{\mathrm{I}}$ is determined from linear elastic fracture mechanics finite element analysis, while the limit load is determined from an iterative finite element analysis.

\section{Fracture parameter}

The X65 fatigue bending specimens considered have developed flaws that are large (beyond plate width, and usually more than half of plate thickness). The irregularshaped flaws will be studied via finite element approach.

\subsection{Stress intensity factor solutions of interest}

In determining the fracture parameter, several available stress intensity factor (SIF) solutions were of interest. This includes BS7910:2013 SIF solutions for the surface semi-elliptical crack in a plate and extended surface flaw [4] and another solution of extended surface flaw under bending [9]. However, these solutions are limited to smaller sized flaws.

\subsection{Finite element model of plate with deep flaws}

The extended finite element method (XFEM) was used to study the deep flaws in the specimen. The approach simplifies conventional finite element crack modelling by allowing for an approximation of cracks without the need for intricate meshing of the crack front.

Measurements were taken at the side edges of the crack front, one-quarter length from the sides, as well as the final crack depth. Based on the available information, the crack profile is built to approximate the actual crack profile (Fig. 5).

The test specimen (cut from a pipe) was modelled as a plate, ignoring effects of pipe curvature as it had a large radius relative to thickness. The length of the model corresponds to the constant bending moment section in four-point bending. One end of the plate model was fixed, while the surface on the other end was constrained to a single point (Fig. 6a). The bending moment was applied to this point.

The mesh was composed of 8-noded reduced integration cubic elements (C3D8R). A finer mesh was used around the crack front (Fig. 6b).

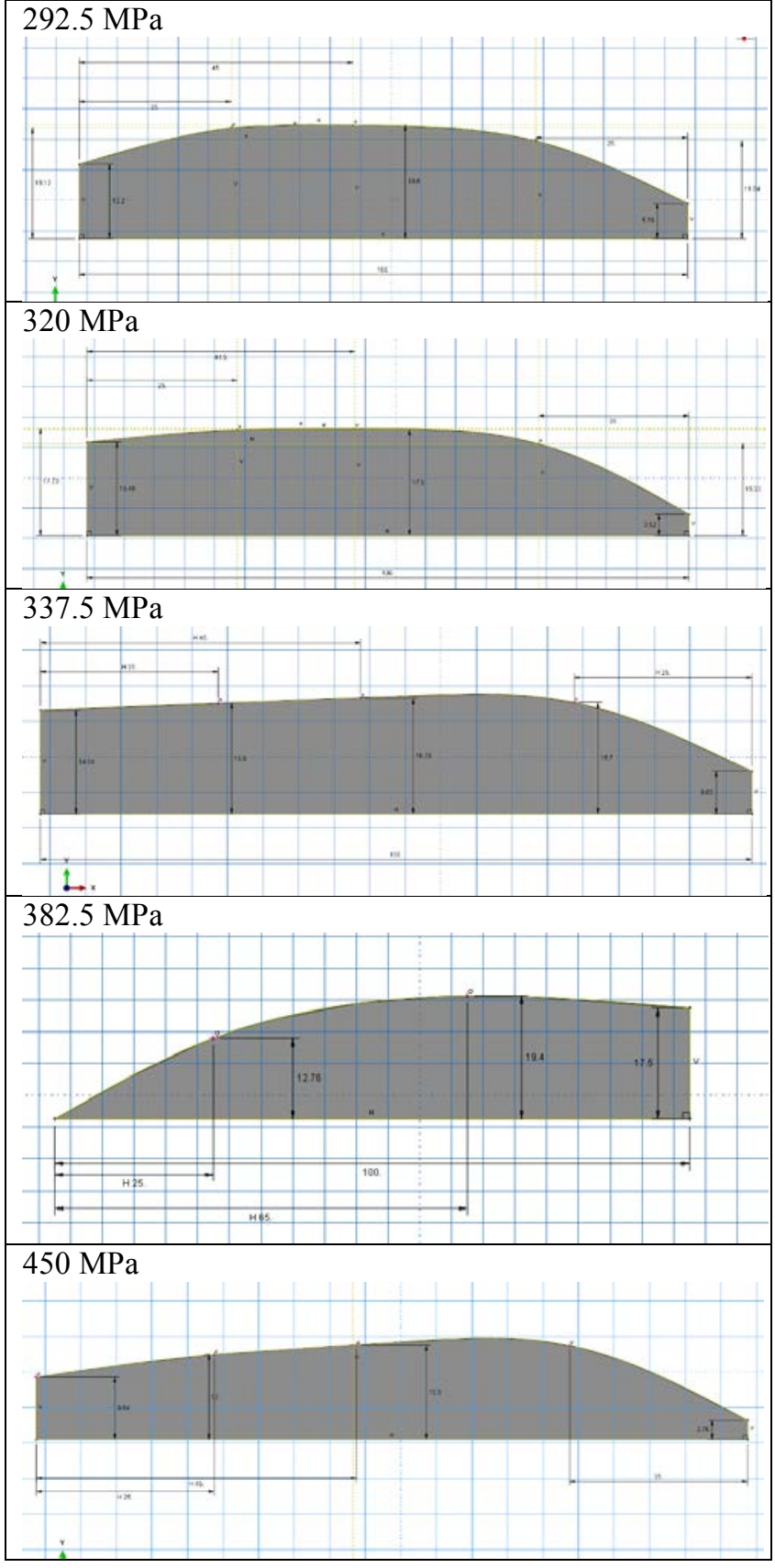

Fig. 5. Measured crack profiles used in finite element model. 


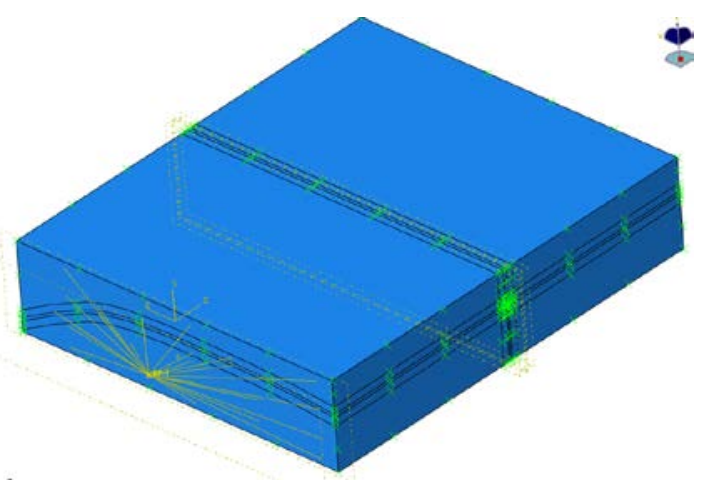

(a) Solid model and boundary condition setup.

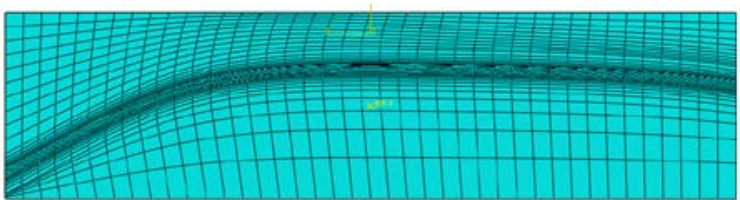

(b) Mesh of crack front

Fig. 6. Model of Specimen 2, of stress range $320 \mathrm{MPa}$.

A sample von Mises stress distribution at the crack plane is shown in Fig. 7. The resulting Y-factors are shown in Table 2, with the SIFs determined from

$K_{I}=Y \sigma \sqrt{\pi a_{i}}$

where $a_{i}$ is the depth of the crack front location from the free surface (Fig. 8).

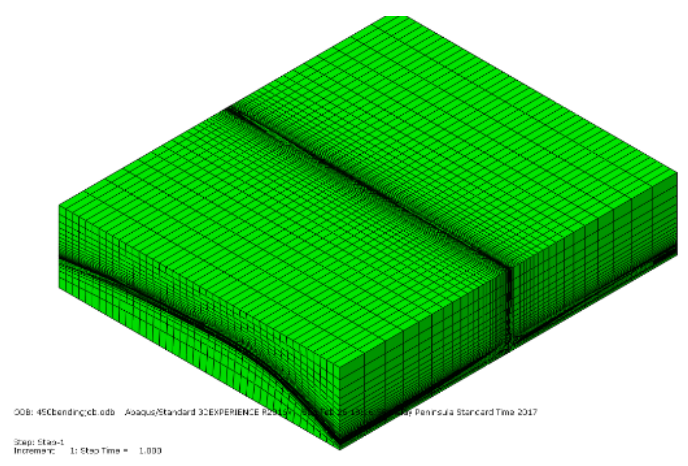

(a) Finite element model

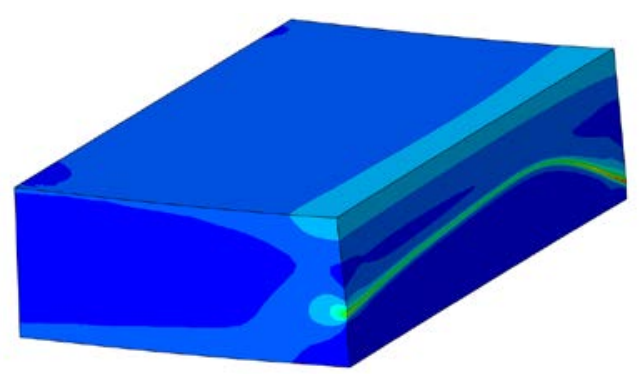

(b) Stress distribution at crack plane

Fig. 7. Model of Specimen 3, of stress range 337.5 MPa.

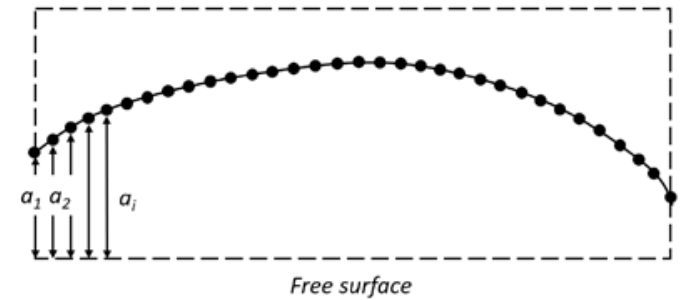

Fig. 8. Depth of crack front location from free surface.

Table 2. Stress range and stress intensity factors (bending)

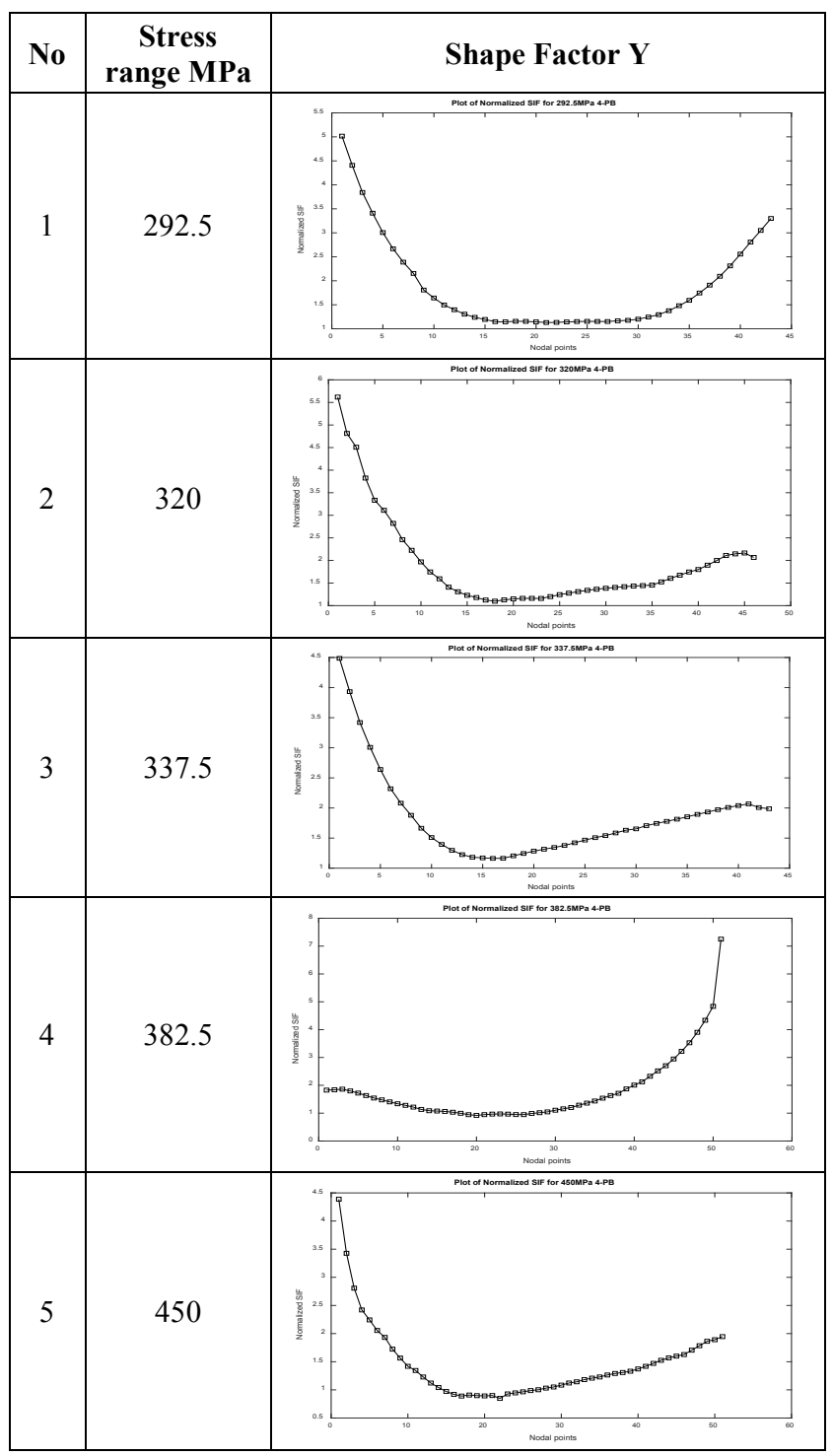

\section{Plastic collapse parameter}

The global limit load refers to the load that would allow unbounded displacements throughout the structure, and is equivalent to the load capacity of the structure. The local limit load refers to the load required to cause complete plasticity in the remaining ligament within the crack plane. 
A possible approach to determine the limit load uses load increment and iteration up to yield [10]. The approach is accurate but computing-intensive.

For each model, incremental load steps were run iteratively until the entire ligament undergoes complete yielding. An example of the final stresses at full ligament yield are shown in Fig. 7. The final stresses at crack profile and sides are shown in Fig. 5. The limit loads determined are tabulated in Table 3.

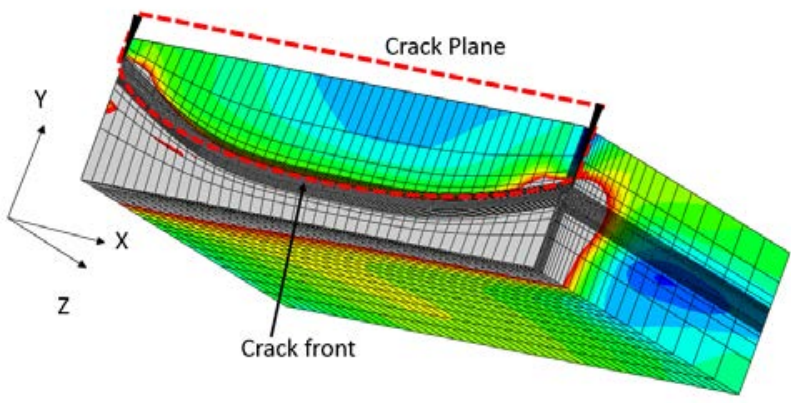

Fig. 7. Stress distribution at full ligament yield (Specimen 1 292.5 MPa)

353.4 MPa Specimen $1-292.5 \mathrm{MPa}$

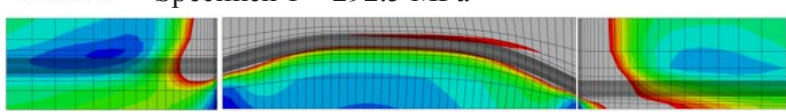

455.701 MPa Specimen 2-320 MPa

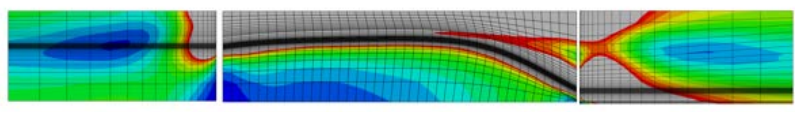

446.4MPa Specimen $3-337.5 \mathrm{MPa}$

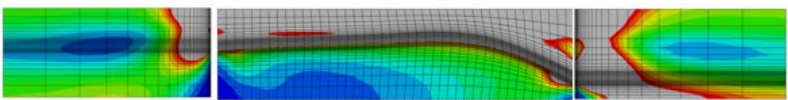

$539.4 \mathrm{MPa} \quad$ Specimen $4-382.5 \mathrm{MPa}$

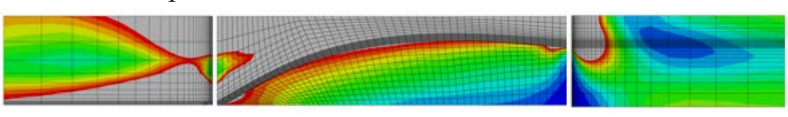

744MPa $\quad$ Specimen 5-450 MPa

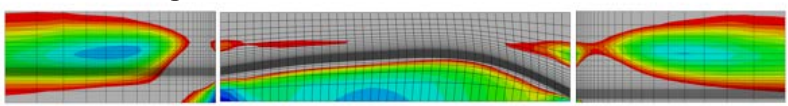

Fig. 8. Crack plane section view to determine local limit load (bending)
Table 3. Limit loads determined by iterative approach

\begin{tabular}{|c|c|c|}
\hline No & $\begin{array}{c}\text { Stress } \\
\text { range MPa }\end{array}$ & $\begin{array}{c}\text { Limit load } \\
\text { (bending) } \\
\text { /MPa }\end{array}$ \\
\hline 1 & 292.5 & 353.4 \\
\hline 2 & 320 & 455.7 \\
\hline 3 & 337.5 & 446.4 \\
\hline 4 & 382.5 & 539.4 \\
\hline 5 & 450 & 744 \\
\hline
\end{tabular}

\section{Failure assessment of $X 65$}

The FAD can be constructed from equations (3) to (7), while the assessment points can be determined from results in Tables 2 and 3, giving Table 4. The stresses were determined for the deepest points and at the free surfaces with highest SIFs at the different loads.

Table 4. Assessment points of X65 steel under bending

\begin{tabular}{|c|c|c|c|c|}
\hline No & $\begin{array}{c}\text { Stress } \\
\text { range MPa }\end{array}$ & $\begin{array}{c}\mathbf{K}_{\mathbf{r}} \text { (free } \\
\text { surface) }\end{array}$ & $\begin{array}{c}\mathbf{K}_{\mathbf{r}} \text { (deepest } \\
\text { point) }\end{array}$ & $\mathbf{L}_{\mathbf{r}}$ \\
\hline 1 & 292.5 & 0.779 & 0.327 & 0.919 \\
\hline 2 & 320 & 0.655 & 0.357 & 0.78 \\
\hline 3 & 337.5 & 0.702 & 0.352 & 0.84 \\
\hline 4 & 382.5 & 0.603 & 0.354 & 0.787 \\
\hline 5 & 450 & 0.520 & 0.310 & 0.672 \\
\hline
\end{tabular}

The assessment points on the FAD (Fig. 9) show that under bending, the cracks at the surface are close to failure or unacceptable, while the points at the crack depth are deemed acceptable.

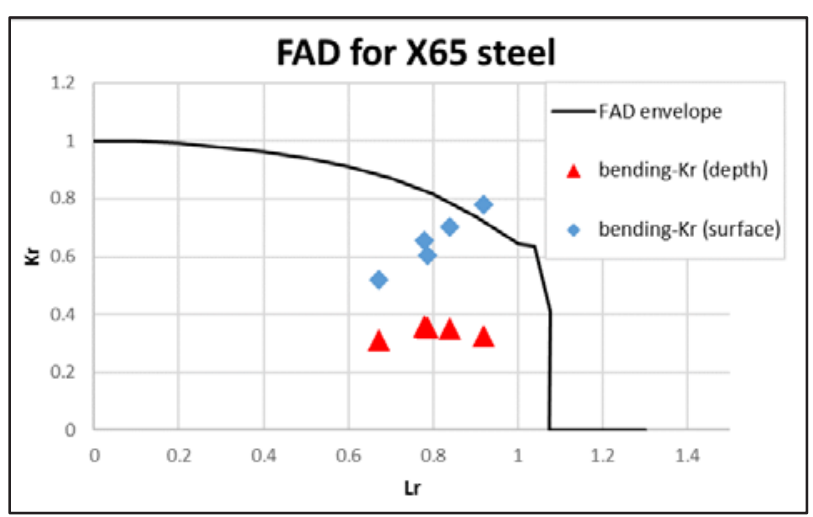

Fig. 9. Failure assessment diagram for X65 with large flaws. 


\section{Conclusion}

The BS7910:2013 solutions are sufficiently accurate for flaws that are small, but become very conservative when large cracks are considered. The current assessment of previously tested X65 specimens with large cracks show local through-thickness yielding is likely to occur before global ligament yielding. The current work demonstrates a more accurate approach to assess large flaws by considering the SIFs and limit loads by finite element analysis.

\section{References}

1. J.H.L. Pang, H.J. Hoh, K.S. Tsang, J. Low, S.C. Kong, W.G. Yuan, Int. J. Fatigue 94 158-165 (2017)

2. J.C. Newman Jr, I.S. Raju, Eng. Fract. Mech. 15 185-192 (1981)

3. H.J. Hoh, J.H.L. Pang, K.S. Tsang, Int. J. Fatigue 87 279-287 (2016)

4. British Standards Institution, BS7910:2013 (2013)

5. S.J. Garwood, R.H. Leggatt, T. Ingham, Fatigue Fract. Eng. Mater. Struct. 17 (1994)

6. M.J. Cheaitani, J. Pipe Eng. 8 149-166 (2009)

7. S.H. Hashemi, Mater. Sci. Eng. A 528 1648-1655 (2011)

8. J. Capelle, J. Furtado, Z. Azari, S. Jallais, G. Pluvinage, Eng. Fract. Mech. 110 270-280 (2013)

9. B. Gross, J.E. Srawley, NASA TN D-2603 (1965)

10. I. Sattari-Far, Int. J. Pres. Ves. \& Piping 57 237-243 (1994) 